\title{
Psychosocial Problems among Parents Caring for Children with Cerebral Palsy Attending a Tertiary Care Hospital in Ile-Ife, South-West, Nigeria
}

\author{
Article by Ganiyu Abiodun Adedeji \\ Ph.D. Public Health, Texila American University, Guyana \\ E-mail: olabode20032001@yahoo.com
}

\begin{abstract}
Background: It has been established that the challenges faced by children with cerebral palsy bring about a higher level of stress which has negative effect on their physical health as well as their social well-being. The aim of this study was to explore the psychosocial problems encountered by the parents caring for children with cerebral palsy $(C P)$ in an urban setting.

Methods: Qualitative research design using focus group discussion (FGD) was used for the study.

The setting was a focus group discussion (FGD) at Obafemi Awolowo University Teaching Hospitals Complex, Ile-Ife, South-West, Nigeria. A total of ten parents participated in the focus group discussion. The parents caring for the children with cerebral palsy coming for treatment in the physiotherapy outpatient clinic of the department were contacted and the nature of the study was explained to them. The main outcome measured were the psychosocial problems encountered by the parents caring for children with cerebral palsy.

Results: The outcome of the study revealed that problems like finance, health-related problems, impaired social relationships, worries concerning child's future and requirement for more support were encountered by the parents of these children. Most of the parents had visited different traditional, spiritual homes as well as health care facilities for solution to their children's problems.

Conclusions. Parents caring for children with cerebral palsy encountered varieties of psychosocial problems. Family centered care program can be designed for cerebral palsy children and their parents based on information that may be obtained from research studies of this nature.
\end{abstract}

Keywords: Psychosocial problems, cerebral Palsy, Parents, Care, Children.

\section{Introduction}

Cerebral palsy (CP), known as Little's disease is a disorder of the central nervous system and it constitutes permanent, non-progressive anatomical damage of the motor centers of the brain which manifests in impairments in both mobility and posture [1]. It has also been defined as a permanent, but not irreversible impairment of muscle tone and movement which is caused by a damage of the evolving nervous system before or during birth or in the first months of life [2]. Cerebral palsy has been estimated to be five to ten times more common in under-privileged parts of the world, but the exact burden is unknown in most low-and middle-income countries as the global incidence is between 2 and 3 per 1000 live births [3].

As cerebral palsy is the most common cause of physical disability in children worldwide, little is reported on the condition in the African context [5]. A recent study in Egypt reported a childhood prevalence of 3.6 per 1000 live births among children less than or equal to 18 years and 0.4 per 1000 live births among adults aged 19-40 years [6]. Another study from Nigeria which is another developing country in Africa found that birth asphyxia (39.0\%), bilirubin encephalopathy (24.4\%) and post infectious brain damage (18.3\%) were the major causes of cerebral palsy [4].

A study carried out in 2014 on psychosocial problems among parents of children with cerebral palsy in Western India revealed a wide range of psychosocial problems that were experienced by the parents of these children. These problems were associated with common themes such as disturbed social relationships, health problems, financial problems, moments of happiness, worries about future of the child, need for more support services, and lack of adequate number of trained physiotherapists [7]. Similarly, Marron et al. in 2013 found out that the most important predictors of caregiver burden were degree of disability, depression and self-efficacy in a study conducted on burden of caregivers of 
children with cerebral palsy in Spain. The authors concluded that it was necessary to develop interventions to reduce depression and enhance self-efficacy in parents of children with cerebral palsy as one of the primary objectives for minimizing the burden on caregivers of disabled children [8].

In a cross-sectional descriptive survey conducted in the Physiotherapy Department of a tertiary hospital in Nigeria, Olawale and his co-researchers [9] found that personal problems that were experienced by parents of children with cerebral palsy included loss of job, lack of concentration at work, loss of family joy as well as derangement of financial affairs of the family. The authors however concluded that families caring for children with cerebral palsy generally had a positive attitude towards their children despite the challenges.

Cheshire et al., [17] conducted a comparative study between parents of children with cerebral palsy and parents of those without a long-term health condition. The study demonstrated that parents of children with cerebral palsy have significantly poorer psychosocial well-being compared with parents of children without a long-term health condition. In a similar study, Dambi et al. [19] aimed to establish the well-being of caregivers of children with cerebral palsy living in high-density areas of Harare in Zimbabwe. Many of the caregivers experienced some form of pain and depression. They were also overwhelmed by the care-giving role.

Till date, little is known about psychosocial problems among parents caring for cerebral palsy children in African countries especially, in Nigeria. It has been established in other countries that parents caring for children with cerebral palsy had experienced various degrees of psychosocial problems [10, $7,1]$. These psychosocial problems have lots of negative impacts on the general well-being of parents of such children. Even though, similar investigations had been done in some other countries of the world before, there is paucity of data in Nigerian urban communities to the best of the researcher's knowledge. Therefore, it is intuitive to find out the various psychosocial problems being encountered by parents caring for cerebral palsy children in a developing country like Nigeria. The outcome from this study can allow further conduct of research in this region so as to develop interventions that can be used to address the problems that may emanate from the study.

\section{Methods}

A qualitative study using focus group discussion (FGD) was carried out. A focus group discussion was carried out at an urban tertiary hospital center involving ten participants. The urban tertiary care hospital is Obafemi Awolowo University Teaching Hospitals Complex (O.A.U.T.H.C), located in Ife central local government area of Osun State, in Nigeria. Ethical clearance for the study was obtained from the Ethics and Research Committee of Obafemi Awolowo University Teaching Hospitals Complex, Ile-Ife. Permission to carry out the study was obtained from the management of the hospital through the head of the department of Medical Rehabilitation of the institution.

The parents caring for the children with cerebral palsy coming for treatment in the physiotherapy outpatient clinic of the department were contacted and the nature of the study was explained to them. The diagnosis of cerebral palsy was based on the information contained in the medical records of the patients that was confirmed by comprehensive assessment by physiotherapists. All those agreeing to participate were included in the study. A round table sitting arrangement was followed during the focus group discussion and it was conducted in a separate room devoid of any disturbances. The rooms were adequately ventilated and had space big enough to accommodate all participants and the researcher. Physiotherapy attendants were saddled with the responsibility of taking care of the participants' children for the duration of the focus group discussion. Video recording was done for the focus group discussion. The consent of each of the participants was obtained before commencing the discussion.

The focus group discussion was conducted by a team of which there was a moderator, an observer with one person responsible for the recordings. The focus group discussion commenced with the moderator introducing the entire team members and this was followed by introduction from the participants. The moderator employed a focus group discussion guide during the focus group discussions of which there were fifteen questions. The questions are as follows:

(1) What are the changes that has occurred in your life after having a child with disability as compared to your previous life?

(2) What are the problems you are facing in day to day life in the upbringing of your child? 
(3) Do you experience feelings like anxiety and depression?

(4) How well do you sleep?

(5) What are the health challenges you encounter presently? Are any of them a result of caring for your child?

(6)What are the kinds of worries you face for the future of your child and for yourself?

(7) Do you have feelings of anger resulting from the problems faced by your child and do you put blame on anyone?

(8) Can you describe periods during which you have felt happiness or satisfaction about your child?

(9) What is the perception of relatives and neighbors concerning your child's problems?

(10) Does the current status of your child have effects on your day to day activities?

(11) Does the current status of your child have effects on your social relationship?

(12) Does the current status of your child have any effect on your marital relationship?

(13) What kind of support have you received from your family, general community, neighbors, school teachers, and health care providers as a result of your child's problem?

(14) What financial problems have you experienced as a result of caring for your child?

(15) What assistance do you expect and from whom during the caring for your child?

All the questions were contained in the focus group guide which had been previously reviewed by experts to ensure the face validity. The duration of the focus group discussion was one hour ten minutes. Preparation of the transcripts was done using the video and audio recordings. Thereafter, the transcripts was analyzed qualitatively using Atlas Ti which is a textual analysis software program [11]. Appropriate codes were assigned to different quotations after the data had been reviewed with the use of the software. Groupings of the codes was done which led to creation of the appropriate themes.

\section{Results}

All the participants in the focus group discussions were parents caring for children with cerebral palsy who were bringing their children for treatment at the department of Medical Rehabilitation of Obafemi Awolowo University Teaching Hospitals Complex, Ile-Ife. They were all females. There were a total of 10 participants in the focus group discussion with mean age of 41.9 years. $5(50 \%)$ of them were traders, $2(20 \%)$ among them were teachers, $1(10 \%)$ of them was a nurse while the remaining $2(20 \%)$ were full housewives. $6(60 \%)$ among them were from monogamous family, while the remaining $4(40 \%)$ were from polygamous family. The mean number of children of the participants is 2.5 and the mean age of their children is 3.6. Male children had a higher number and percentage [6(60\%)], while the remaining $4(40 \%)$ were females. These sociodemographic characteristics is as shown in Table 1. When the transcript of the focus group discussion was analyzed, these themes surfaced.

\section{(a). Psychosocial problems relating to parents' social activities}

All the participants in the focus group discussion reported a common problem having to do with reduction in their participation in social gatherings like naming, marriage and other ceremonies. They reported having difficulties interacting with relatives and such interactions were restricted to their own homes because they could not visit relatives' houses. Many of the participants suffered from lack of understanding from the society generally. There were reports of constant questioning from friends and relatives focusing on the length of time of treatment as well as the prognosis of the condition of the child. Those questions increased the stress and worries of the parents. A mother participating in the study reported as follows: 'Since I encountered this problem with my child, I have not been able to attend important ceremonies even in the community where I live. Many of my friends kept on asking me for how long will I continue to treat my child for this condition. This question has been difficult for me to answer'. There were reports that caring for the cerebral palsy child consumes a lot of their time which affected other house activities. Few of the participants reported that their child's problem had affected their marital relationships leading to constant misunderstanding between the husband and wife. 


\section{(b) Psychosocial problems relating to child care}

The participants claimed to experience a multitudes of problems in the process of caring for the child. They claimed to be busy doing one thing or the other for the child. They reported that it was always difficult to keep the child with just anyone else. Inability of the children to communicate made the process of care worse. They carry food and water everywhere they were going with the child in order to satisfy their needs. One of the participants reported thus: 'my child is unable to sit on her own and cannot crawl, stand or walk on her own. I used to lift her every time. Her cries makes me unable to sleep most of the times'

\section{(c) Psychosocial problems relating to finance}

All participants emphasized that money played an essential role in the caring of their child. Among the various spendings are the doctor's and physiotherapist's consultation including purchase of drugs and physiotherapy habilitation and rehabilitation gadgets including transporting the child. Sometimes, as the child was more disabled, parents had to hire a separate vehicle each time in order to bring the child to and from the clinics.

Many of them had to travel almost every day for obtaining physiotherapy and occupation therapy services for their children. One of the parents claimed that she had to employ the services of house girl specifically to be able to give better care for the child. This contributed to increased financial burden. Another participant's lamented in her report: 'Things are so hard for me and my husband that we found it difficult to bring her for physiotherapy. I have been asked to purchase some habilitation gadgets for her physiotherapy but, due to lack of enough money, we have not been able to get all of them. My home is far from this hospital and transport money is a big problem on its own. I am almost fed up. I felt I had not given birth to her'.

\section{(d) Parents' health challenges}

Among the main health challenges of the parents are pains in the back and the upper limbs. This was attributable to carrying and lifting of the child on regular occasions. Headache due to laborious caring for the child was reported by few participants. Four of the parents also reported experiencing insomnia on regular occassions. Another participant report is as follows: 'My child usually has stiff muscles all over the body and he cannot move by himself. I do almost everything for him. I will feed him, bath for him, lift him every time and clean him after soiling his nappies. It is difficult for me handling him with my other children. I am always tired with persistent headaches'.

Various psychological challenges were also reported by the Parents. They reported feelings of negative emotions in the form of anger, tiredness and frustration.

\section{(e) Societal perception of the cerebral palsy child}

There were many negative comments about the cerebral palsy child. Such comments had been unpalatable to parents who felt uncomfortable with the negative comments. Sometimes, the parents reported that they used to feel that very few people supported them and that society was against them in general. In some cases, people refer to their children as mentally retarded children which made the parents unhappy. Even though many relatives and neighbours make comments that were unpalatable, there were few who were very compassionate and supportive in their bid to care for their children. This report is from another participant: 'my friends used to laugh whenever I am struggling handling him because he is a difficult child. I am not usually happy about this but, I only pretend to them as if I am not feeling bad. My husband's family members are not happy with me thinking that I brought this kind of child to their family'.

\section{(f) Problems encountered in seeking for health care services}

All the parents (participants) reported that they had visited health care providers both traditional and orthodox prior to getting the right specialist that could successfully rehabilitate their children. The parents were of the opinion that there is scarcity of health care professionals who can and are willing to provide appropriate rehabilitation to these children. One mother reported thus: 'I had initially suffered in the hands of traditional healers before I eventually discovered physiotherapy. Some of them had 
requested for killing of rams, making sacrifices that are against my religious belief. A lot of incisions were made on my child all of which had no positive results'.

However they felt satisfied when the child demonstrated improvement after receiving treatment from physiotherapists. There were reports of good attention from physiotherapists which they claimed had boosted their morale as parents caring for these children. Majority of the participants reported that they were getting commendable improvement in their children's condition as compared to when they started. Some reported improvement in activities while others reported improvement in feeding and interacting with peers. Almost all the participants lamented on the unavailability of special schools for their children. They claimed that the few that are available are too far from their residence.

\section{Discussion}

All the participants in this study were females and were the biological mothers caring for the cerebral palsy children being managed in the physiotherapy out-patient clinic of the department of medical rehabilitation, O.A.U.T.H.C., Ile-Ife, Nigeria. This finding is contrary to the work of Nimbalka and his associate researchers [7] where they reported one participant to be the grandmother and another participant to be a father of the cerebral palsy child. Many psychosocial problems being faced by parents caring for children with cerebral palsy were uncovered during the focus group discussion.

There were positive and negative responses from the society concerning their children's condition which brought about psychosocial problems to the parents. The child was neglected in some cases and adverse comments were made by the society. This finding was similar to the finding of a qualitative study conducted by Neely-Barnes et al. [12] with parents of children with autism, cerebral palsy, sickle cell disease and Down's syndrome where many cases of discrimination from society and family were reported. It also corroborate the report of Singogo et al. [18] whose study reported mothers of children with cerebral palsy feeling socially isolated due to a lack of support from the family, community members and health care providers. This study revealed that the stress of taking care of cerebral palsy children negatively affected the parents' social relationship with the members of their families, including their relatives and neighbours. This actually increased the parents' psychosocial problems. This has to do with the time-consuming nature of the care. The finding is in line with the report of the study conducted by Davis and his co-researchers [13].

There were many psychological and emotional problems encountered by parents caring for children with cerebral palsy leading to increased psychosocial problems. Among these problems are sleep disturbances and suicidal tendencies. The outcome of this study corroborates the work of Sajedi et al. in 2010 which showed that having a child with cerebral palsy is associated with higher prevalence and severity of depression among mothers [14]. The above findings is also supported in a study conducted by Gallagher and his co-researchers where it was revealed that parents of children with intellectual disabilities attained high depression and anxiety scores and that majority of them met the criteria for possible clinical depression and anxiety when compared to parents of normal children [15].

One of the important findings from the parents who participated in this study is the report of their encounter with back pain and aches which invariably increased the parents' psychosocial problems. This was attributed to constant lifting and carrying of the children. The outcome of the work of Brehaut and co-researchers in a study conducted in Canada is in line with the above findings from this study. In that study, it was reported that the primary caregivers of children with cerebral palsy reported an increased likelihood for numerous physical health problems especially, back pain [16].

The participants in this study reported inadequate availability of health care professionals for habilitation and rehabilitation of the children affected with cerebral palsy. This finding was supported by the outcome of a study by Davis et al.[13] where insufficient support services for managing the children condition was reported. The work of Nimbalka et. al. [7] also support the finding from the present study where they reported that there were lack of adequate doctors and other health care specialists for habilitation and rehabilitation of the cerebral palsy children. This finding also corroborate the outcome of a study [20] where the authors reported inadequate facilities and services, unsupportive interactions, limitation of parents' social relations and social seclusion of the child and parents as the main challenges for parents of children with cerebral palsy. 
DOI: $10.21522 /$ TIJPH.2013.06.01.Art004

ISSN: $2520-3134$

\section{Conclusion}

This study uncovers a wide range of health, social as well as psychological problems being encountered by the parents caring for children with cerebral palsy in a tertiary hospital setting in Nigeria. These problems ranged from stress, anxiety, depression, back pains to negative perception from the society, finance as well as inadequate number of health professional specialists. It is recommended that every efforts must be put in place to alleviate the psychosocial problems being encountered by parents caring for children with cerebral palsy in order to prevent compromise of the health of these caregivers which might negatively affect the care of the cerebral palsy children.

\section{Figures and tables}

Table 1. Socio-demographic characteristics of parents and the children

\begin{tabular}{|l|}
\hline \multicolumn{1}{|c|}{ Item Number Percentage } \\
\hline Participants \\
Total number of participants 10.0 \\
Male $0.00 .0 \%$ \\
Female $10.0100 .0 \%$ \\
Occup age of participants (years) 41.9 \\
Trading $5.050 \%$ \\
Teaching $2.020 \%$ \\
Nursing $1.010 \%$ \\
Full Housewife $2.020 \%$ \\
Nature of family \\
Polygamy $4.040 \%$ \\
Monogamy $6.060 \%$ \\
Mean number of children 2.5 \\
Participants' children \\
Mean age of the children (years) 3.6 \\
Sex \\
Female $4.040 \%$ \\
Male $6.060 \%$ \\
\hline
\end{tabular}

\section{References}

[1]. Alaee N, Shahboulaghi FM, Khankeh H and Kermanshahi SM (2015). Psychosocial Challenges for the Parents of Children with Cerebral Palsy: A Qualitative Study. Journal of Child and Family Studies.

[2]. Cheshire A, Barlow JH and Powell LA (2010). The Psychosocial Well-being of Parents of Children with Cerebral Palsy: A Comparative Study. Disability and Rehabilitation, 32(20), 1673-1677.

El-Tallawy HN, Farghaly MA, Shehata GA, Rageh TA, Metwally NA, Badry R, Sayed AM, Abd El Brehaut JC, Kohen DE and Rainad P (2004) "The health of primary caregivers of children with cerebral palsy: how does it compare with that of other Canadian caregivers?” Pediatrics, 114, (2), e182-e191. 
[3]. Donald KA, Kakooza AM, Wammanda RD, Mallewa M, Samia P, Babakir H, Bearden D, Majnemer A, Fehlings D, Shevell M, Chugani H and Wilmshurst JM (2015).

[4]. Davis E, Shelly A, Waters E, Boyd R, Cook K and Davern M (2010). "The impact of caring for a child with cerebral palsy: quality of life for mothers and fathers," Child: Care, Health and Development, 36 (1), 63-73.

[5]. Dambi, JM, Jelsma J \& Mlambo T (2015). Caring for a child with Cerebral Palsy: The experience of Zimbabwean mothers, African Journal of Disability 4(1), Art. \#168. http://dx.doi.org/10.4102/ajod.v4i1.168.

[6]. Gulam K, Hayley S, Johurul I, Monzurul A, Jenny J, Iona N, Robert B, Cheryl J, Nadia B and Mohammad M (2015). Bangladesh Cerebral Palsy Register (BCPR): a pilot study to develop a national cerebral palsy (CP) register with surveillance of children for CP. BMC Neurol, 15, 173.

[7]. Gallagher S, Phillips AC, Oliver C and Carroll D (2008). "Predictors of psychological morbidity in parents of children with intellectual disabilities," Journal of Pediatric Psychology, 33, (10), 1129-1136.

[8]. Hamed M, Abd-Elwarth A, Kandil MR (2014). Cerebral palsy in Al-Quseir City, Egypt: prevalence, subtypes, and risk factors. Neuropsychiatric Disease and Treatment, 10, 1267-1272.

[9]. Hodapp MR (1998). Advancing Finding, Theories, and Methods Concerning Children with Disabilities. Athens: Cambridge University Press.

[10]. Marrón, EM, Redolar-Ripoll D, Boixadós M, Nieto R, Guillamón N, Hernández E (2013). Burden on caregivers of children with cerebral palsy: Predictors and related factors. Universitas Psychologica, 12(3), 767777.

[11]. Majnemer A, Shevell M, Law M, Poulin C and Rosenbaum P (2012). Indicators of distress in families of children with cerebral palsy. Disabil Rehabil, 34(14), 1202-1207.

[12]. Neely-Barnes SL, Graff JC, Roberts RJ, Hall HR and Hankins JS (2010). "“It's our job': qualitative study of family responses to ableism," Intellectual and Developmental Disabilities, 48(4), 245-258.

[13]. Nimbalkar S, Raithatha S, Shah R, Panchal DA (2014). A Qualitative Study of Psychosocial Problems among Parents of Children with Cerebral Palsy Attending Two Tertiary Care Hospitals in Western India. ISRN Family Med, doi: 10.1155/2014/769619.

[14]. Ozmen M, Caliskan M, Apak S, Gokcay G (1993). 8-Year clinical experience in cerebral palsy. J Trop Pediatr, 39, 52-54.

[15]. Olawale OA, Deih A N and Yaadar RK (2013). Psychological impact of cerebral palsy on families: The African perspective. J Neurosci Rural Pract. 4(2): 159-163.

[16]. Scientific Software Development, "Atlasti the knowledge work-bench," Berlin, Germany, http://www.atlasti.com/.

Pediatric Cerebral Palsy in Africa: Where Are We? J Child Neurol, 30(8), 963-971.

[17]. Sajedi F, Alizad V, Malekkhosravi G, Karimlou M and Vameghi R (2010). "Depression in mothers of children with cerebral palsy and its relation to severity and type of cerebral palsy," Acta Medica Iranica, 48(4), 250-254.

[18]. Singogo C, Mweshi M and Rhoda A (2015). Challenges experienced by mothers caring for children with cerebral palsy in Zambia. South African Journal of Physiotherapy. 71(1).

[19]. Thanou E, Tsiou C, Kattami C, Chrousos GP \& Darviri C (2016). A Stress Management and Health Promotion Intervention for Parents of Children with Cerebral Palsy and Motor Disability at the Infant Department of the Greek Center for the Protection and Rehabilitation of the Disabled (ELEPAP). Quasi-Experimental Study. Psychology, 7, 557-564. 